\title{
Transmission Performance of Spectral Amplitude Code Optical Code Division Multiple Access with Using RZ Format
}

\author{
Krishma Bakshi ${ }^{*}$, Himali Sarangal and Dr. Jyoteesh Malhotra \\ Department of Electronics and Communication Engg., GNDU Regional Campus, \\ Jalandhar-144008, Punjab. India \\ *Corresponding Author E-mail: bakshikrishma@gmail.com
}

\begin{abstract}
Optical correspondence for different access has turn into the standard for scientists as the utility rate in optical correspondence these days is expanding quickly. As different gets to, the more clients uses the system, date rate, limit and security have turn into the discriminating issue for the optical framework. The development of remote correspondence with code-division multiple access (CDMA) system have persuaded the joining of CDMA method into optical system, as it is substantially more alluring since it permits different users in a local area network (LAN) environment to get to the same fiber channel non concurrently at all times. Besides, the power of CDMA method in remote system is yet to demonstrate that OCDMA offers security preferences over other various access frameworks by keeping up the nature of administrations. In this paper, the study on OCDMA is in light of exhibiting an analysis on Optical Spectral-Amplitude Code (SAC) OCDMA organized with uniform fiber Bragg gratings. It shows a three-clients SAC-OCDMA For three-client SAC-OCDMA system working at $1550 \mathrm{~nm}$ wavelength with $622 \mathrm{Mb} / \mathrm{s}$ information rate and $10 \mathrm{Gchip} / \mathrm{s}$ chip rate, the greatest suitable transmission separation for a bit mistake rate $(B E R)<10-9$ at $50 \mathrm{~km}$ SMF utilizing RZ group [8].
\end{abstract}

Keywords: OCDMA, SAC-OCDMA, MAI

\section{Introduction}

Vast limit, high velocity are currently sought after in correspondence with optical systems which permit numerous clients to have the same optical fiber transmission capacity. Among various access strategies, optical code division multiple access (OCDMA) is getting more alluring in the field of every single optical correspondence as numerous clients can get to the system non concurrently and all the while because of the abnormal state of transmission security, huge transfer speed, and low lessening and it can subsequently encourage numerous administrations, for example, astounding feature transmission OCDMA is a multiplexing method by which every correspondence channel is recognized by a particular optical code as opposed to a wavelength or a period openings. An encoding operation optically changes every information bit some time recently transmission. At the beneficiary, the opposite translating operation is obliged to recoup the first data [1].The encoding and unraveling operation alone constitute optical coding. Among a few sorts of OCDMA frameworks, spectral amplitude coding scheme pulls in expanding interest on the grounds that multiple access interference (MAI) can be wiped out. In such a framework, the optical range is sufficiency coded by an alternate code for every channel to create the OCDMA signals. The incomprehensible source shows up as a decent contender for SAC as it is naturally broadband, an important normal for SAC. 


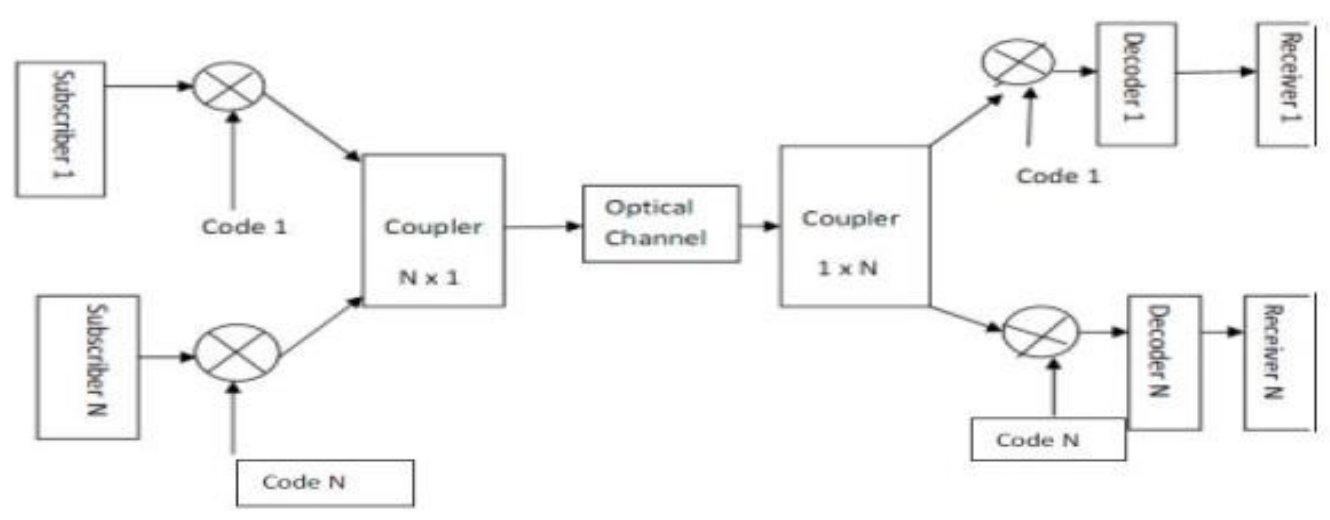

Figure 1. Basic Block Diagram of OCDMA

An OCDMA framework for every client can be depicted by an information source, containing the information that will be sent, trailed by an encoder and afterward a laser that maps the sign from electrical structure to an optical heartbeat arrangement. At the recipient end, an optical correlator is utilized to concentrate the encoded information. Numerous endorsers transmit information at the same time. Every client has its own particular codeword, which is roughly orthogonal to all other code words. The encoded information is send to the $\mathrm{N}^{*} 1$ star coupler, from where the optical channel brings the sign through the optical fiber and couples to a $1 * \mathrm{~N}$ coupler and show to all hubs. All clients encoded information are then included chip by chip and the outcome, which is known as the superposition, are sent over the channel. The vicinity of the light heartbeat speak to the twofold bit '1'and the unlucky deficiency of the light heartbeat speak to the double bit ' 0 '. The individual beneficiaries comprising of optical correlator consistently watch the superposition of all approaching heartbeat transmission and recuperate the information from the comparing transmitter This is finished by connection between the approaching flag and put away duplicates of that client exceptional grouping. The correlator will give a top, if the approaching stream of optical heartbeats contains the exceptional grouping and the vicinity of different clients will be considered as noise. The translating procedure is refined by utilizing optical relationship. The collector performs a period connection operation to identify just the particular fancied codeword.

\section{System Description}

The optical yield of a broadband optical source is digitally regulated by the client information signal utilizing Mach-Zhender modulator. The recurrence parts of the balanced optical sign are encoded by specifically transmitting them as per a mark code. Three uniform fiber Bragg gratings (FBGs), having the same data transmission and distinctive Bragg wavelengths, are utilized to get the three mark codes, one to every client. The tweaked yield signals from the optical modulators are joined utilizing a 3:1 optical combiner whose yield is dined into the fiber. A routine (standard) single mode fiber (SMF) is utilized at the transmission connection between the transmitter and collector. The optical force toward the end of the transmission connection is part into three sections utilizing a 1:3optical splitter, each relates to one client. The client optical sign is then part to two segments utilizing 1:2 optical splitter. 


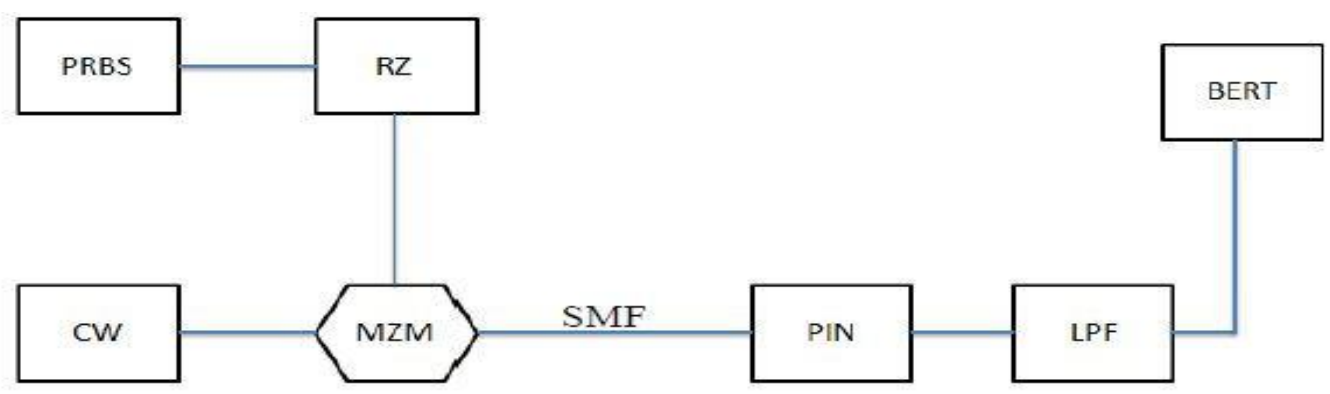

Figure 2. SAC OCDMA in Opti System

\section{Methodology}

\section{SAC OCDMA}

We have utilized SAC OCDMA to stifle the limit of OCDMA which is Multiple Access Interference (MAI).Among a few sorts of OCDMA frameworks, spectral amplitude coding (SAC) plan draws in expanding interest in light of the fact that multiple access interference (MAI) can be disposed of. In such a framework, the optical range is plentifulness coded by an alternate code for every channel to produce the OCDMA signals. The indiscernible source shows up as a decent possibility for SAC as it is inalienably broadband, an essential normal for SAC. Consequently, SAC-OCDMA framework was proposed as a result of its capacity to take out the impact of MAI by utilizing codes with altered as a part of stage cross-relationship. As of late, SAC plan of OCDMA has been acquainted with wipe out the MAI impact and protect the orthogonality between clients in the framework. The SAC-OCDMA frameworks allot one extraordinary ghastly plenty fulness codeword for every system client to code the sufficiency of light source range. Commotions existing in the SAC-OCDMA frameworks incorporate shot commotion, phase-induced intensity noise (PIIN), warm clamor, etc.

\section{System Analysis}

Table 1. Simulation Parameters

\begin{tabular}{|l|l|}
\hline \multicolumn{1}{|c|}{ Parameter } & \multicolumn{1}{|c|}{ Value } \\
\hline $\begin{array}{l}\text { Operating wavelength } \\
\text { region }\end{array}$ & $1550 \mathrm{~nm}$ \\
\hline Signal bit rate & $622 \mathrm{mbps}$ \\
\hline Signal Format & $\mathrm{RZ}$ \\
\hline Fiber length & $50 \mathrm{KM}$ \\
\hline $\begin{array}{l}\text { Receiver filter } \\
\text { bandwidth }\end{array}$ & 0.65 bit rate $=130$ \\
\hline $\begin{array}{l}\text { Photodiode quantum } \\
\text { efficiency }\end{array}$ & 1 \\
\hline $\begin{array}{l}\text { Optical Modulator } \\
\text { extinction ratio }\end{array}$ & $30 \mathrm{~dB}$ \\
\hline
\end{tabular}

\section{Results and Discussions}

The received eye diagram of user1 after $50 \mathrm{~km}$ transmission is shown in Figure 3. Note that the eye diagram is almost opened which insures low bit error rate (BER). The BER is found to be $1.29 * 10^{-9}$ and this is to be compared with $10-9$ which is used as the maximum allowable value in optical communication system. 


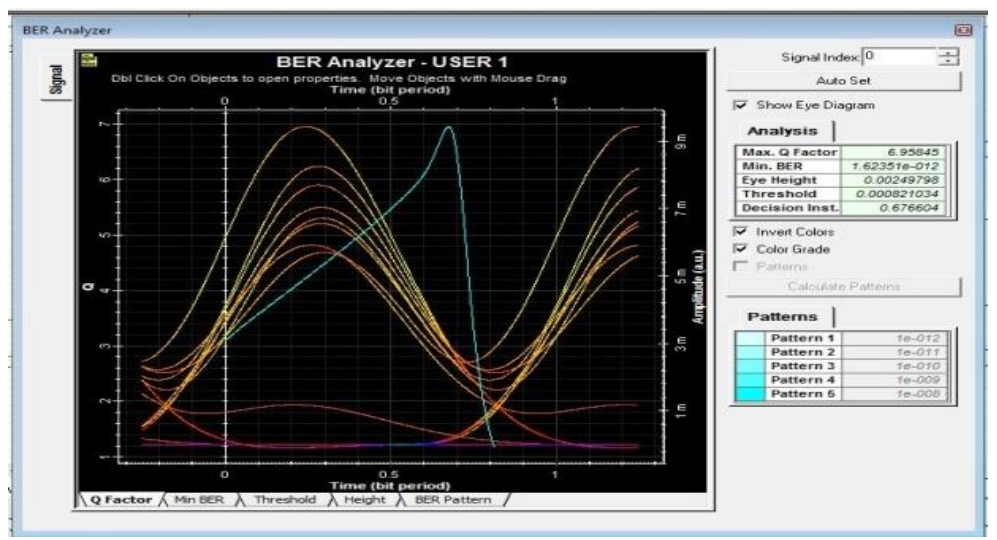

Figure 3. Eye Diagram of User 1after 50km Transmission

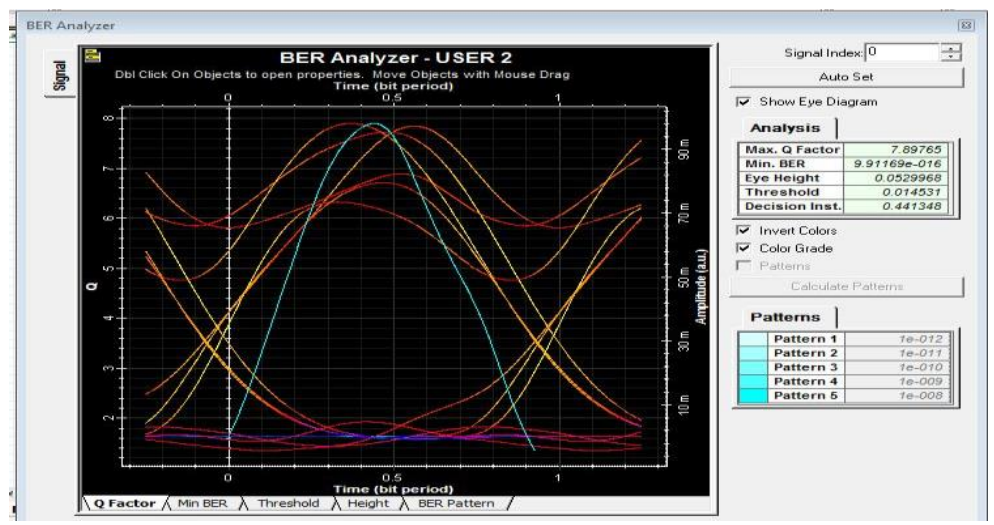

Figure 4. Eye Diagram of User 2 after $50 \mathrm{~km}$ Transmission

Now in Figure 4, the received eye diagram of user 2 after $50 \mathrm{~km}$ transmission is shown. Note that the eye diagram is almost opened which insures low bit error rate (BER).

The maximum allowable transmission distance for a bit error rate (BER) $<10-9$ is about $50 \mathrm{~km}$ and this is to be compared with $10-9$ which is used as the maximum allowable value in optical communication system for user 3 as shown in Figure 5.

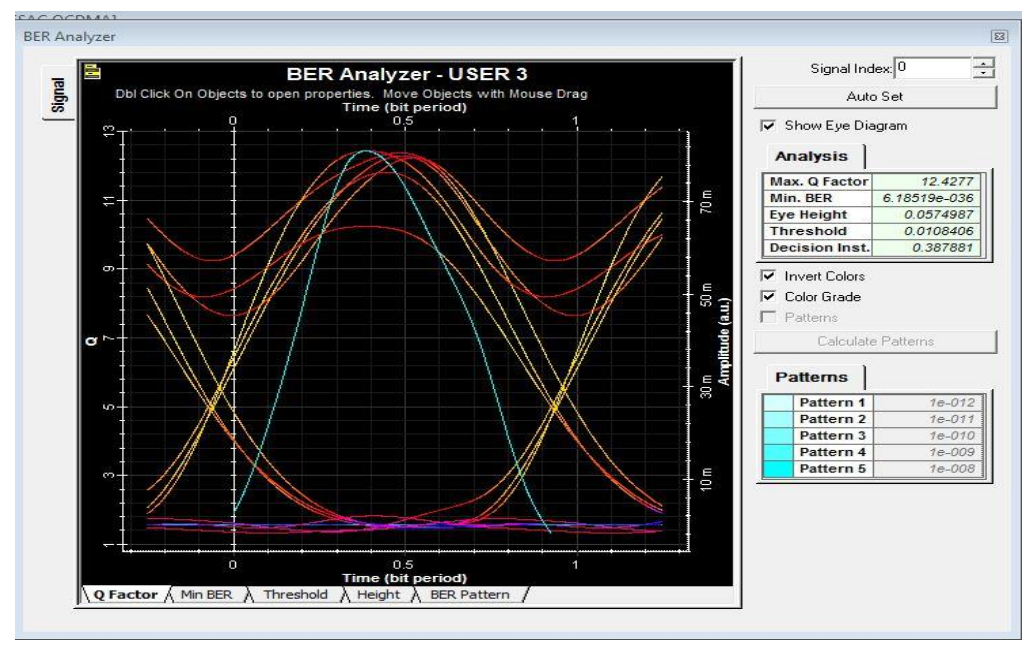

Figure 5. Eye Diagram of User 3 after $50 \mathrm{~km}$ Transmission 
The graphical representation of transmission of the two different fibre lengths i.e., $30 \mathrm{~km}$ and $50 \mathrm{~km}$ for three different users respectively as shown in Figure 6, shows the variations in the BER, the BER as a function of fiber length for the three users.

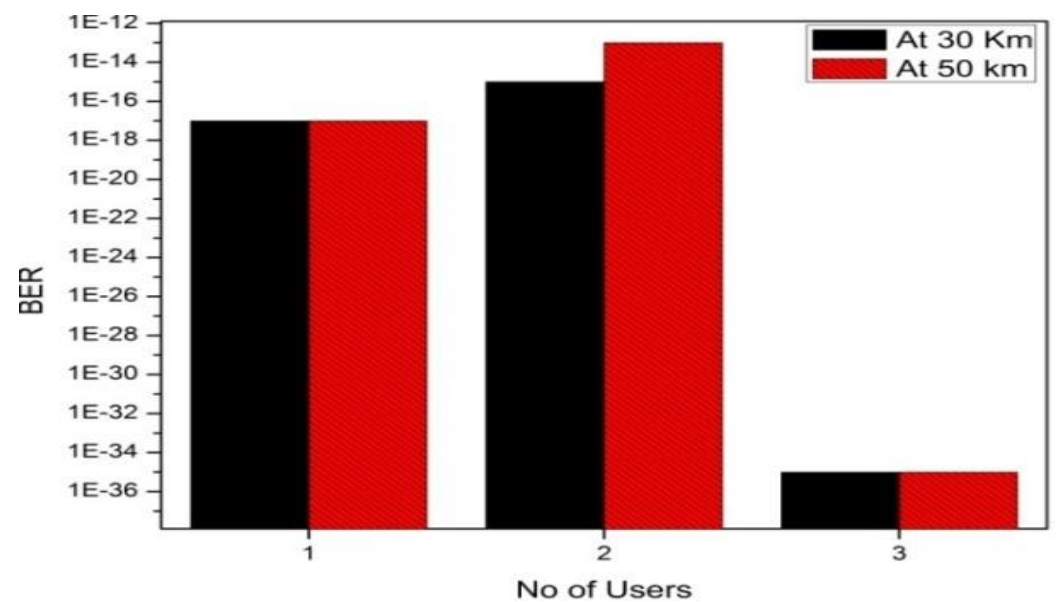

Figure 6. Variation of BER with Fiber Lengths $30 \mathrm{~km}$ and $50 \mathrm{~km}$

\section{Future Work}

In future, the performance of SAC OCDMA can be analysed by considering the other photodetector impairments like surface leakage current and dark current. Also, suitable encoder/decoder architecture can be designed for the proposed codes like one dimensional, two dimensional codes. Further, these codes can be tested for use in wireless optical system.

\section{Conclusion}

The execution of SAC-OCDMA system working with $622 \mathrm{Mbps}$ information rate and $10 \mathrm{Gchip} / \mathrm{s}$ chip rate has been researched to address the impact of transmission through a solitary mode fiber of length $50 \mathrm{KM}$ utilizing RZ format. The greatest permissible transmission separation for a bit error rate (BER) $<10-9$ is around $50 \mathrm{~km}$. Besides, SACOCDMA coordinates Optical coding strategies to build the quantity of supporters and the security levels of the system. The outcomes demonstrate that the execution of fiber opticbased SAC-OCDMA system can stifle t he MAI due to low bit rate and high Q factor.

\section{Acknowledgement}

The author wishes to thanks Mrs. Himali Sarangal for the guidance provided in this research work.

\section{References}

[1] S. Olonkins, V. Bobrovs and G. Ivanovs, Electronics Electrical Eng., vol. 7, no. 133, (2012).

[2] G. Arora and S. Dewra, International Journal of Electronics and Communication Engineering Research, vol. 1, no. 6, (2013).

[3] H. Bhagwan, T. Gulati and B. Rawat, International Journal of Engineering Research and Applications (IJERA), vol. 2, no. 663, (2012).

[4] M. M. J. Martini, C. E. S. Castellani, M. J. Pontes, M. R. N. Ribeiro and H. J. Kalinowski, Proceedings of SBMO/IEEE MTT-S International Microwave and Optoelectronics Conference (IMOC), Belem, Brazil, (2009) November 3-6.

[5] S. Singh and R. S. Kaler, Optik 123, 1636, (2012).

[6] A. Sheetal, A. K. Sharma and R. S. Kaler, "ELSEVIER Optic international journal for light and electron optics", vol. 121, no. 739, (2010). 
[7] M. M. Lodro and M. A. Joyo, "Proceedings of International Conference on Information and Computer Networks", (ICICN), Singapore, (2012) February 26-28.

[8] G. Kaur, M. L. Singh and M. S. Patterh, "Emerald Journal of Engineering, Design and Technology", vol. 8 , no. $28,(\mathbf{2 0 1 0})$.

[9] V. Bobrovs, S. Olonkins, O. Ozolins, J. Porins and G. Lauks, OSA Publications, 3rd Fiber Optics in Access Network - FOAN, St Petersburg, Russian Federation, (2012) October 3-4.

[10] V. Bobrovs and G. Ivanovs, Latvian Journal of Physics and Technical Sciences, vol. 45, no. 3, (2008).

[11] M. Anuar, S. Aljunid, N. Saad and S. Hamzah, "New design of spectral amplitude coding in OCDMA with zero cross-correlation", Optics Communications, vol. 6, no. 13, (2009) March, pp. 2659-2664.

[12] H. Yin and D. J. Richardson, "Optical code division multiple access communication networks", Tsinghua University Press, Beijing and Springer-Verlag GmbH Berlin Heidelberg, (2007).

[13] M. Noshad and K. Jamshidi, "Code family for modified spectral-amplitude-coding OCDMA systems and performance analysis", Journal of Optical Communication Network, vol. 2, no. 6, (2010) June, pp. 344-354.

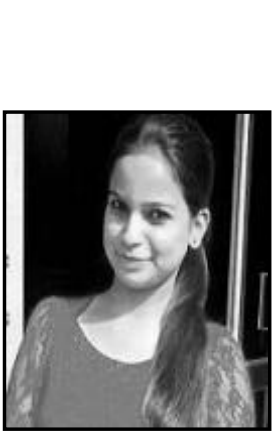

\section{Authors}

Krishma Bakshi*, (B.Tech) received the Bachelors degree in Electronics and Communication Engineering, in 2014. Currently, she is a student of M.Tech in Electronics and Communication, specialization in communication systems Department at Guru Nanak Dev University, Regional Campus, Jalandhar Punjab (INDIA). Her research area of interest is Optisystem, wireless and network security by optical fibers.

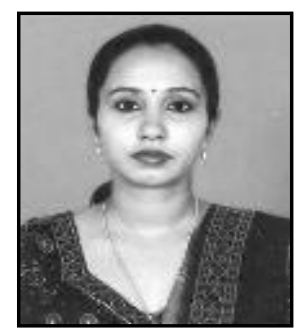

Himali Sarangal, (BTech, MTech) is involved in teaching and research in Electronics and Communication Department at Guru Nanak Dev University Regional Campus Jalandhar, India. Her research area of interest includes optical communication and wireless communication. She has more than 40 research publications.

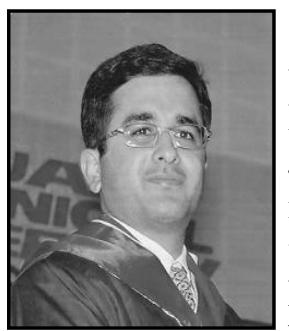

Jyoteesh Malhotra, (BTech, MTech, PhD) is involved in teaching and research in Electronics and Communication Department at Guru Nanak Dev University Regional Campus Jalandhar, India. His research area of interest includes statistical modeling of fading channels, Fading mitigation techniques in wireless communication, wireless networks, and wireless BAN. Dr. Malhotra has more than 100 research publication and authored two books. He is a life member of ISTE and editorial board member of many international journal of repute. 